\title{
SHOCK WAVE PROPAGATION IN AN OBSTRUCTED AREA
}

\author{
ANTOINE GAUTIER ${ }^{1}$, ISABELLE SOCHET ${ }^{1}$, EMMANUEL LAPEBIE $^{2} \&$ AZAD BOUBRIT $^{2}$ \\ ${ }^{1}$ Institut National des Sciences Appliquées Centre Val de Loire, Université d'Orléans, France \\ ${ }^{2}$ CEA, DAM, GRAMAT, France
}

\begin{abstract}
The aim of this study is to characterize the behaviour and propagation of a shock wave in an obstructed area. The recent literature demonstrates the attenuation of shock wave versus the obstacle shape and matrix arrangement. The paper will present an experimental work conducted at a small scale. The shock wave is created from the detonation of a hemispherical gaseous charge confined in a bubble on a surface. The obstruction zone is obtained by rigid vertical cylinders in an open area. Influences of distribution and areal density of the cylinders as function of the mass of explosive charge are investigated. The blast wave is characterized by using pressure sensors and a high-speed camera. Hence, the pressure sensors acquired overpressure and the arrival time. The propagation and reflexion, diffraction of shock wave, are analysed from the pictures produced during the visualization tests.

Keywords: shock waves, cylinders, experiments, shock/obstacles interaction, obstruction.
\end{abstract}

\section{INTRODUCTION}

Accidental or terrorist explosions in urban landscape have been more and more present this last years despite the increase of cautions. One can cite the explosion at the AZF plant in Toulouse (2001) or the suicide-attack near the Stade de France (Paris, 13 November 2015). Actually, the zero risk does not exist; therefore, it is important to understand the effects of the explosion, including the interaction between blast wave and the environment. Indeed, the blast wave propagation in an obstructed area (urban configuration) is a complex phenomenon that depends on a large number of parameters. The most common effects are the mitigation or the increase of physical properties like overpressure and positive impulse.

Experimental and numerical investigations have led to a considerable amount of knowledge about shock wave and obstacles interaction. The first effect of this interaction is the shock wave reflection. All reflection phenomena experimentally observed were reported by Ben-Dor [1], with analytical analysis. Thus, it is well known that reflections can increase overpressure (Wang et al. [2]) and positive impulse (Fouchier et al. [3], Rose and Smith [4]). Nevertheless, multiple reflection with multiple obstacles configurations was investigated in order to mitigate overpressure. Chaudhuri et al. [5] numerically investigated geometrical parameters of obstacle matrices on shock wave propagation. They observed, like did Berger et al. [6], that obstacle geometry with divergent effect is more efficient to mitigate the transmitted shock wave while obstacle geometry with convergent effect is more efficient to mitigate the reflected shock wave. As a result, Skews et al. [7] suggested trapping shock wave in a duct with first rows of convergent obstacles followed by rows of divergent obstacles. By confirming the results of Chaudhuri et al. [5], Wan et al. [8] showed that the obstacles with circular section are not the most efficient to mitigate shock wave. However, obstacles with circular section represent a good approximation of actual environment in urban configuration (poles, trees, traffic lights, humans...). Therefore, particular attention has been paid on the interaction of a shock wave with an array of circular cylinders. Chaudhuri et al. [5], Wan et al. [8], Rogg et al. [9], Epstein and Kudryavtsev [10] Abe et al. [11] and Suzuki et al. [12] all investigated numerically or experimentally the interaction of a shock wave in a shock tube with circular cylinder array. In their numerical study, reproduced by Wan et al. [8], Chaudhuri 
et al. [5] simulate the interaction of a shock wave with a cylinder array $\{4 \times 4\}$ (among other obstacle geometries) in a shock tube. Their results showed about $40 \%$ of overpressure attenuation without almost no difference between the staggered arrangement and the regular arrangement for the circular geometry. Rogg et al. [9] focused on the turbulent effect of the boundary layer and the shock formed by a jet between cylinders in a matrix $\{3 \times 5\}$. They also noted that for the same porosity and arrangement, the cylinder diameter has little or no effect on the overpressure mitigation. Epstein and Kudryavtsev [10] observed numerically the increase of the overpressure attenuation with the decrease of the gap between cylinders forming a porous barrier. Abe et al. [11] experimentally observed interferograms of shock wave propagation in a cylinder matrix $\{5 \times 5\}$ with staggered arrangement in a shock tube. Finally, Suzuki et al. [12] experimentally studied the interaction of a shock wave with different cylinder array and arrangement. They observed the influence of the gap between cylinder on the overpressure attenuation and the weak difference between the regular and the staggered arrangement. Nevertheless, even if in some of these studies, the amount of parameters is large, no one consider a three dimensional configuration, i.e. where cylinders have a finite height.

In this study, we consider the explosion of a gaseous charge in an open area where some cylindrical obstacles obstruct the shock wave propagation. The experiments are performed in small-scale, using pressure sensors and high-speed camera to obtain measurements. It has been demonstrated that small-scale experiments are correlated with large-scale experiments (Rigby et al. [13]). Moreover, the experimental setup used for this study has a good repeatability (Maillot et al. [14]). The description of this experimental setup will be the first part of this document. The analysis of the three configurations of obstruction will then be presented: a matrix $\{4 \times 2\}$ and two matrices $\{6 \times 6\}$, one with a regular arrangement and one with a staggered arrangement. A last synthetic part will show the impact of the obstructed area on the shock wave propagation.

\section{EXPERIMENTAL SETUP}

\subsection{Experimental bench}

In this study, the experiments are carried out in reduced scale. The experimental setup is the same as used by Maillot et al. [14], i.e. it is made of a table, an ignition device, a pressure measurement system and an optical bench.

The table forms a flat perforated surface on which the hemispherical gaseous charge is placed. The perforated holes allow the installation of the ignition device and the pressure sensors. The ignition device is a high voltage system with a tinned copper wire attached between two electrodes, as detailed by Langlet et al. [15]. The explosive charge is a stoichiometric gaseous mixture of propane and oxygen $\left(\mathrm{C}_{3} \mathrm{H}_{8}+5 \mathrm{O}_{2}\right)$. The mixed gas is injected in a soap bubble whose radius is controlled by a circular metallic ring.

The optical bench is set up in order to perform shadowgraph visualizations like detailed by Hargather and Settles [16]. This method exploits the deflection of light rays to project the shadow of the shock wave thanks to a retro-reflective screen and a light source coaxed with the optical axe (Fig. 1). A high-speed camera Phantom V7.3 is used to capture the shock wave propagation, with a sample rate of $16,877 \mathrm{pps}$. The resolution of the pictures is $688 \times 256$ pixels to visualize a real frame of $665 \mathrm{~mm}$ of width and $247 \mathrm{~mm}$ of height. 


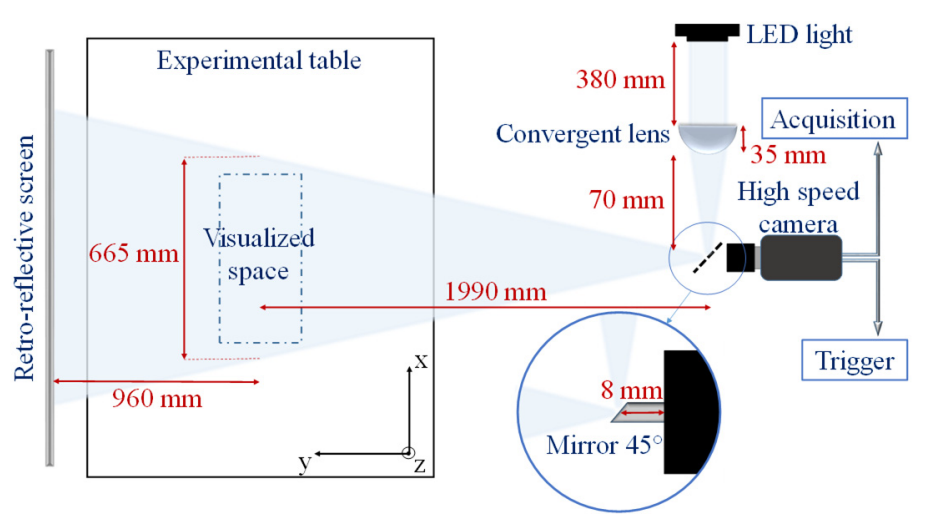

Figure 1: Optical bench schema.

\subsection{Measurement equipment}

As mentioned next, the shock wave is tracked by two different means. The first one consists of measuring the overpressure with pressure sensors and the second one is the visualization. The pressure sensors used are piezoelectric PCB 113B26 (+/- 1.3\% of incertitude). The pressure recording starts $1 \mathrm{~ms}$ before the trigger and stops $5 \mathrm{~ms}$ after the trigger with a sampling rate of $1 \mathrm{MHz}$. The trigger is synchronised with the detection of the first peak overpressure produced by the high voltage discharge of the ignition device. The sensors layout is a bit different for the first obstruction configuration and the two others and will be detailed below. Nevertheless, for all configurations, one pressure sensor (sensor L) is positioned in free field to control the validity of each test. Some sensors are situated in the obstructed region and last sensors are laid out downstream the obstructed area.

In order to track shock waves by visualization, a high-speed camera Phantom V7.3 is used. The pictures bring qualitative information very useful to name phenomena observed by the pressure sensors. Once recorded, pictures can be processed with the camera software PCC 3.3.

\subsection{Obstruction configurations}

In this study, we investigate three different obstruction configurations (Fig. 2). Each obstruction is defined as circular cylinder matrices in a reference area. Cylinders are made of wood, with a smooth surface; their diameter is $18 \mathrm{~mm}$ and their height is $82 \mathrm{~mm}$. In all configurations, the gap, i.e. the distance between two cylinders is $18 \mathrm{~mm}$.

The first configuration $\mathrm{C} 1$ is an obstruction configuration with height cylinders, as presented in Fig. 2(a). A first row of four cylinders is positioned front to the charge at 253 $\mathrm{mm}$ from the charge centre. A second row of four cylinder is situated $100 \mathrm{~mm}$ downstream the first one so that each cylinder is positioned $100 \mathrm{~mm}$ behind another one.

The second configuration $\mathrm{C} 2$ is an obstruction configuration with thirty-six cylinders. In this configuration, presented in Fig. 2(b), cylinders form a squared matrix $\{6 \times 6\}$. The face of the closest cylinder from the explosive charge is at $205 \mathrm{~mm}$ to the charge centre.

The third configuration C3, detailed in Fig. 2(c), is the same as the configuration C2 but with a staggered arrangement. The first, the third and the fifth row are in the same place as in the configuration $\mathrm{C} 2$. 


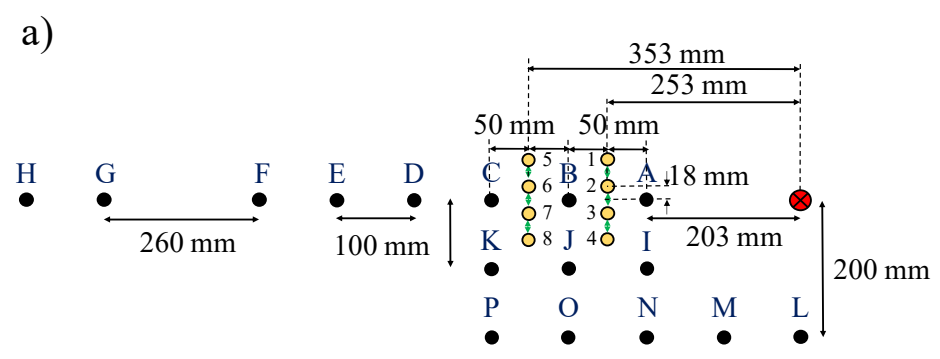

b)
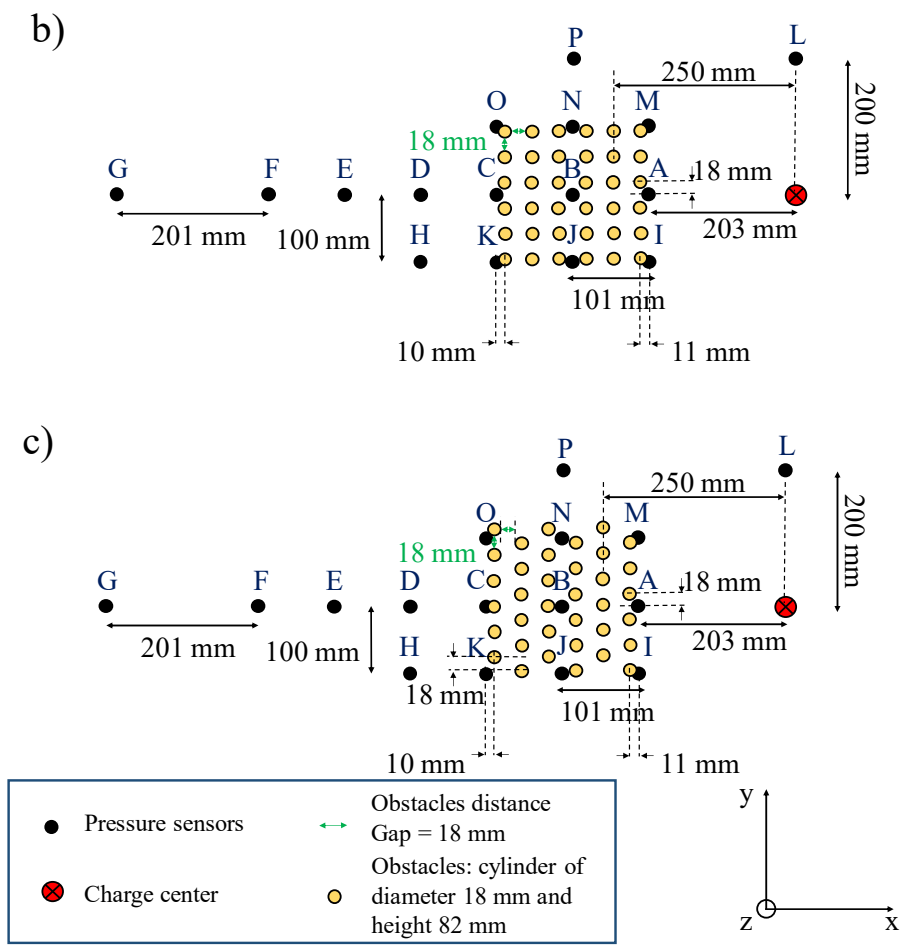

Figure 2: Obstacles and pressure sensors layout. (a) Configuration $\mathrm{C} 1$; (b) Configuration $\mathrm{C} 2$; and (c) Configuration $\mathrm{C} 3$.

\section{SHOCK WAVE PROPAGATION INSIDE THE OBSTACLES AREA}

The propagation of a shock wave through a porous medium is a complex phenomenon. In order to see the effects of the shock wave interaction with all cylinders inside the obstructed area, the overpressure measured by the sensors A, B and C are analysed. In the configurations $\mathrm{C} 2$ and $\mathrm{C} 3$, sensor $\mathrm{A}$ is situated just at the entrance and sensor $\mathrm{C}$ just at the exit of the cylinder matrix while sensor B is at the middle. Therefore, several cylinders surround this last one in all directions. The main effect of the shock wave interaction with the obstacles is its reflection from each one. Consequently, the pressure sensors measure several overpressure peaks for all reflections. In this study, the first peak is named incident shock overpressure and the others are called reflected shock overpressure. 
The pressure-time and the total impulse-time history of the sensors A, B and C for the configurations $\mathrm{C} 1, \mathrm{C} 2$ and $\mathrm{C} 3$ are presented in Fig. 3. The diagrams 3(a), 3(b) and 3(c) show the measurements of sensor $\mathrm{A}$ from the configurations $\mathrm{C} 1, \mathrm{C} 2$ and $\mathrm{C} 3$ respectively. As the first row of obstacles is the same for each configuration $\mathrm{C} 2$ and $\mathrm{C} 3$, the pressure signal and the impulse are almost the same despite the different arrangement downstream the first row. The presence of the high reflection increases considerably the maximum overpressure $(25 \%)$ and the total impulse compared to the free field values.

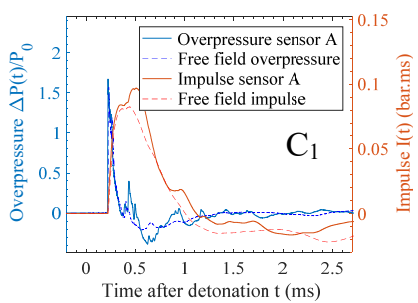

(a)

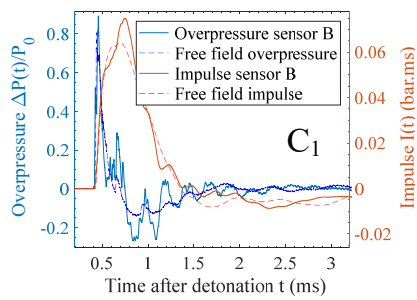

(d)

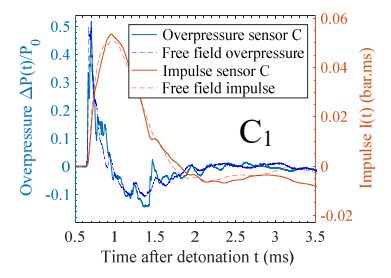

$(\mathrm{g})$

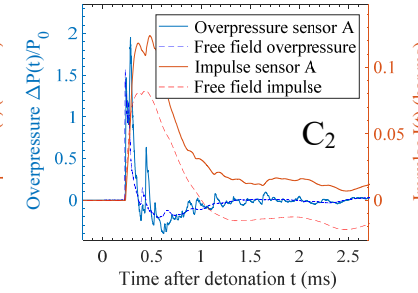

(b)

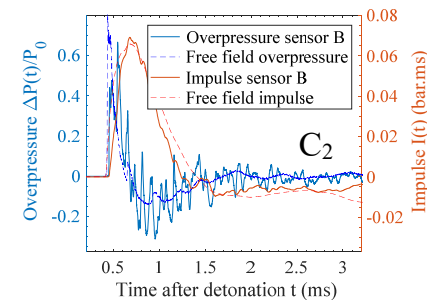

(e)

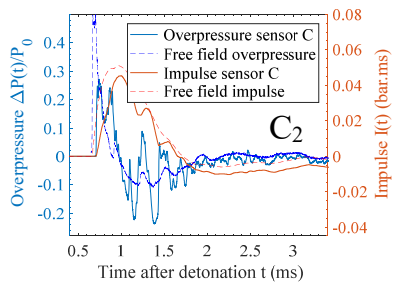

(h)

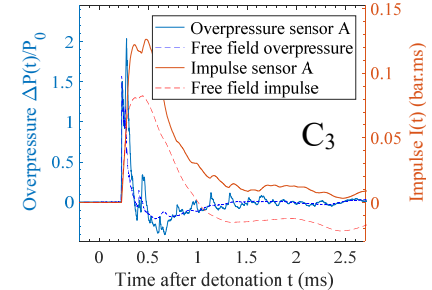

(c)

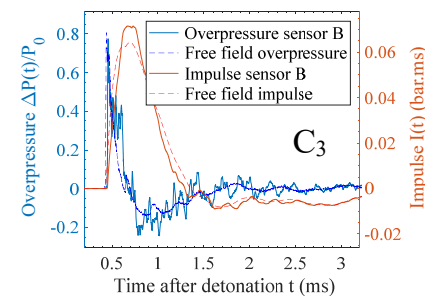

(f)

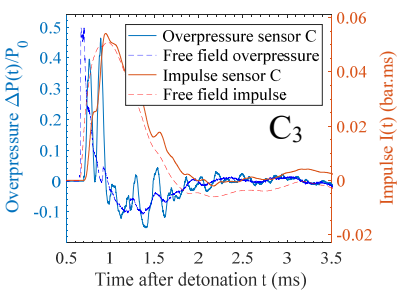

(i)

Figure 3: Pressure-time and impulse-time history of the sensors $\mathrm{A}, \mathrm{B}$ and $\mathrm{C}$. Configurations: left: $\mathrm{C} 1$; middle: $\mathrm{C} 2$; right: $\mathrm{C} 3$.

Concerning sensor B into the middle of the obstructed area, diagrams 3(e) and 3(f) demonstrate the complexity of reflection phenomenon recording the crossing of all reflected shock waves inside the configurations $\mathrm{C} 2$ and $\mathrm{C} 3$ respectively. This phenomenon is more visible for the regular arrangement (C2). In this case, despite the attenuation of the first overpressure peak, the total impulse is similar to the free field model because of reflections.

Finally, the diagrams 3(g), 3(h) and 3(i) illustrate the measurements of sensor $\mathrm{C}$ for the configurations $\mathrm{C} 1, \mathrm{C} 2$ and $\mathrm{C} 3$ respectively. In the configuration $\mathrm{C} 2$, the maximum overpressure is largely mitigated compared to the free field value (45\%). Nevertheless, the total impulse stays near the free field value due to reflections. 
In order to support the analysis of overpressure profiles, some pictures extracted from visualization are presented in Fig. $4(\mathrm{C} 1)$ and Fig. $5(\mathrm{C} 2, \mathrm{C} 3)$. Visualized pictures are processed using image subtraction in imageJ software (https://imagej.net). In Fig. 4, shock waves are visible between the two rows of cylinders. Crossing the first row of cylinders, the incident shock wave is split in three kinds of shock wave: one part is reflected (RS), one part is transmitted across cylinders (TS) and one part diffracts on the top of cylinders (DS). Then, transmitted shocks waves charge the second rows of cylinders and interact in the same way as did IS with the first row. From Fig. 5(a) and 5(b) the shock wave reflections on the first row of cylinders are similar for the configuration $\mathrm{C} 2$ and $\mathrm{C} 3$ as seen previously with the overpressure profiles of sensor A. However, in Fig. 5(c) and 5(d), the way the shock wave leaves the blocking patterns $\mathrm{C} 2$ and $\mathrm{C} 3$ respectively is different. The regular arrangement of the configuration $\mathrm{C} 2$ splits the incident shock wave in a large amount of weak transmitted shock wave. The staggered arrangement of the configuration C3 merges all shock wave reflections in a lower amount of stronger transmitted shock wave.

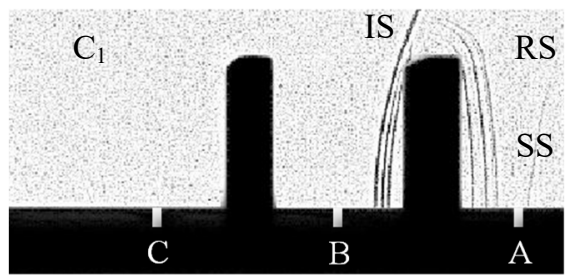

(a)

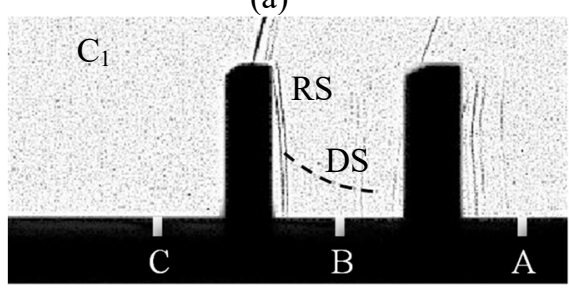

(c)

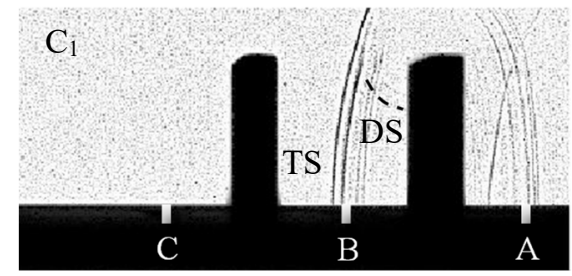

(b)

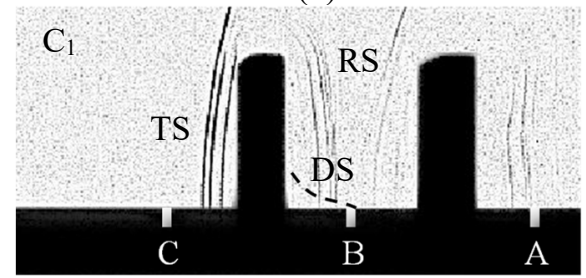

(d)

Figure 4: Experimental visualization after processing of configuration C1. (a) $t=0.367$ $\mathrm{ms}$; (b) $\mathrm{t}=0.426 \mathrm{~ms}$; (c) $\mathrm{t}=0.544 \mathrm{~ms}$; and (d) $\mathrm{t}=0.603 \mathrm{~ms}$. IS: incident shock; RS: reflected shock; SS: secondary shock; TS: transmitted shock; DS: diffracted shock.

The evolution of the maximum overpressure and of the positive impulse against the reduced distance are illustratedSin Fig. 6. F.jg. 6(a) and 6(b) show that, inside the obstructed area (sensor B), the maximum overpressure is reached by reflection phenomenon. Moreover, at the exit of the obstacles area (sensor $\mathrm{C}$ ), the maximum overpressure measured is close to the free field value in $\mathrm{C} 1$ and $\mathrm{C} 3$ while the maximum overpressure is mitigated (40\%) in $\mathrm{C} 2$ compared to free field. The results presented in Fig. 6(e) and 6(f) show that the positive impulse is modified by the same way for the two configurations C2 and C3. As seen previously, at the entrance, positive impulse is considerably increased compared to free field (50\%). Moreover, unlike the total impulse, the positive impulse stays more important than the free field values everywhere inside the obstructed area (more than 25\%). Fig. 6(d) shows 


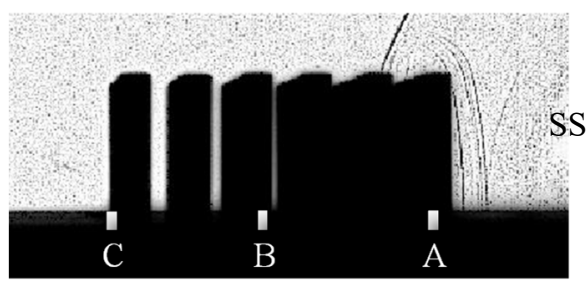

(a)

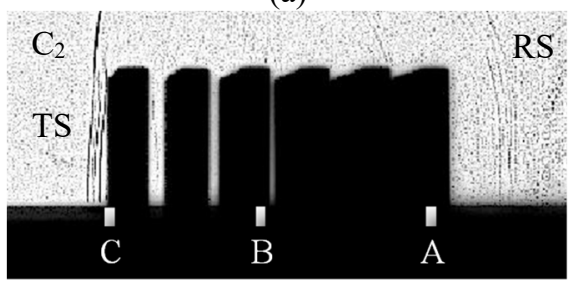

(c)

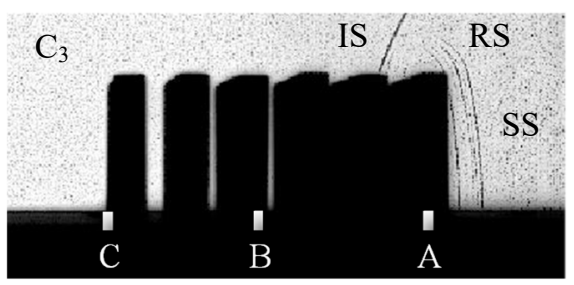

(b)

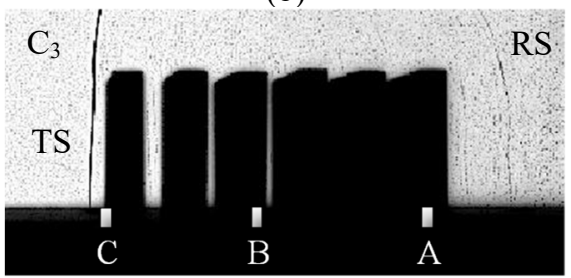

(d)

Figure 5: Experimental visualization after processing. Configurations: left: $\mathrm{C} 2$; right: C3. (a) $\mathrm{t}=0.320 \mathrm{~ms}$; (b) $\mathrm{t}=0.319 \mathrm{~ms}$; (c) $\mathrm{t}=0.734 \mathrm{~ms}$; and (d) $\mathrm{t}=0.733 \mathrm{~ms}$. IS: incident shock; RS: reflected shock; SS: secondary shock; TS: transmitted shock.

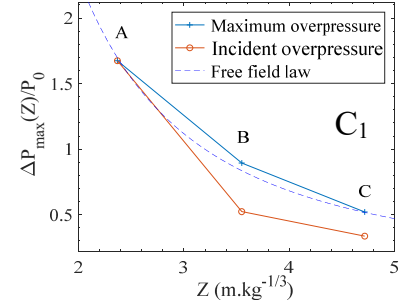

(a)

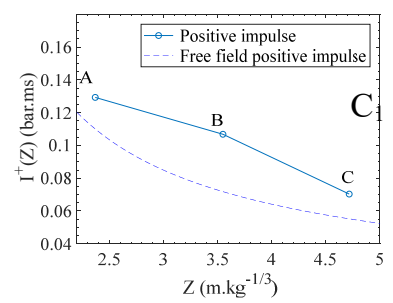

(d)

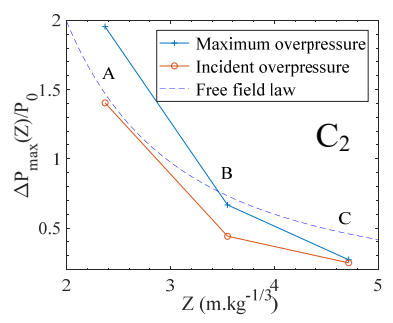

(b)

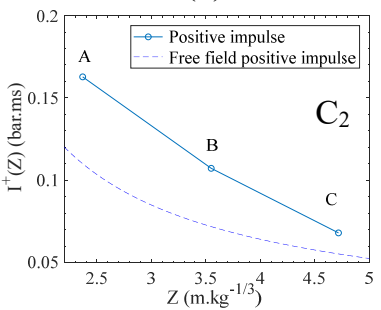

(e)

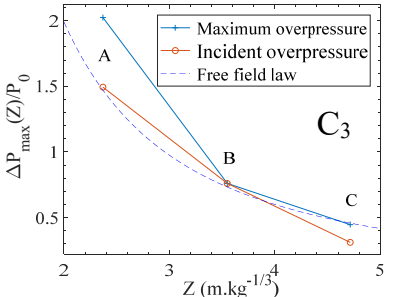

(c)

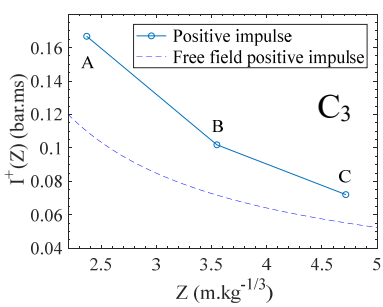

(f)

Figure 6: Maximum overpressure and positive impulse against the reduced distance inside the obstructed area. Configurations: left: $\mathrm{C} 1$; middle: $\mathrm{C} 2$; right: $\mathrm{C} 3$. 
that in the configuration $\mathrm{C} 1$, the positive impulse is increased at sensor $\mathrm{B}$ because of reflections against the second row of cylinders.

The reduced distance $Z$ is defined by the distance divided by the cubic root of the charge mass. By definition, its unit is $\mathrm{m} \cdot \mathrm{kg}^{-1 / 3}$. The free field values of the over polynomial laws established in the laboratory Prisme during this study estimate pressure and the positive impulse, within the range $Z \in[2.3,12.4]$ :

$$
\frac{\Delta P(Z)}{P_{0}}=\exp \left(A_{0}+A_{1} \ln (Z)+A_{2} \ln (Z)^{2}\right)
$$

for the overpressure with:

$$
\begin{gathered}
A_{0}=2.2338 \\
A_{1}=-2.1608 \\
A_{2}=0.1593
\end{gathered}
$$

and:

$$
\frac{I^{+}(Z)}{\sqrt[3]{m}}=\exp \left(B_{0}+B_{1} \ln (Z)+B_{2} \ln (Z)^{2}+B_{3} \ln (Z)^{3}\right)
$$

for the positive impulse with $m$ the charge mass and:

$$
\begin{gathered}
B_{0}=1.5622 \\
B_{1}=-1.9594 \\
B_{2}=0.6052 \\
B_{3}=-0.1122
\end{gathered}
$$

\section{IMPACT OF THE OBSTRUCTED AREA ON THE SHOCK WAVE PROPAGATION}

As seen previously, the incident shock wave (IS) is divided in several transmitted shock wave (TS) at the exit of the configurations $\mathrm{C} 1, \mathrm{C} 2$ and $\mathrm{C} 3$. In addition, the incident shock wave (IS) crosses obstruction getting over obstacles. This part of IS interacts with all tops of cylinders and diffracts on these. The emergence of these diffractions (DS) is the main difference compared with 2D studies performed in shock tubes. In order to evaluate the influence of obstruction of configurations $\mathrm{C} 1, \mathrm{C} 2$ and $\mathrm{C} 3$ on downstream area, measures of sensors D, E, F and $\mathrm{G}$ are analysed.

Fig. 7 represents the signals of overpressure and impulse measured by sensor D against time after detonation for the configurations C2 and C3. Fig. 7(a) and 7(b) show that the maximum overpressure is reached after the first peak of overpressure. This maximum overpressure is equal to the free field maximum overpressure. After the two first peaks, a third peak is observed in the negative phase of the overpressure profile. Then, the overpressure oscillates around the free field values. Therefore, the total impulse is the same as in free field configuration. Unlike just at the exit of the obstructed area (sensor C), the overpressure signal of sensor D is similar in $\mathrm{C} 2$ and $\mathrm{C} 3$. This observation is also valid for the total impulse.

Visualizations of Fig. 8 and Fig. 9 show the difference of the shock waves shapes between configurations $\mathrm{C} 1, \mathrm{C} 2$ and $\mathrm{C} 3$ near and far downstream the obstacles configuration respectively. In Fig. 8, transmitted wave pattern shows a large amount of TS whatever the configuration. A diffracted shock wave DS is clearly visible downstream the last row of cylinders, but this phenomenon happens for all rows so that it results in a combination of reflected waves, as it is visible in Fig. 9. This last figure shows that far from the obstructed area, transmitted waves merge to form a single wave. 


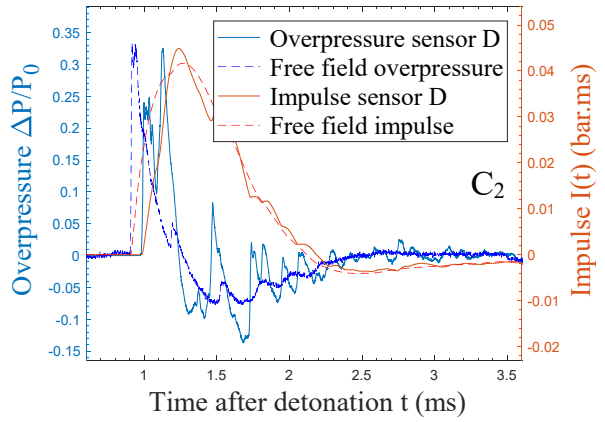

(a)

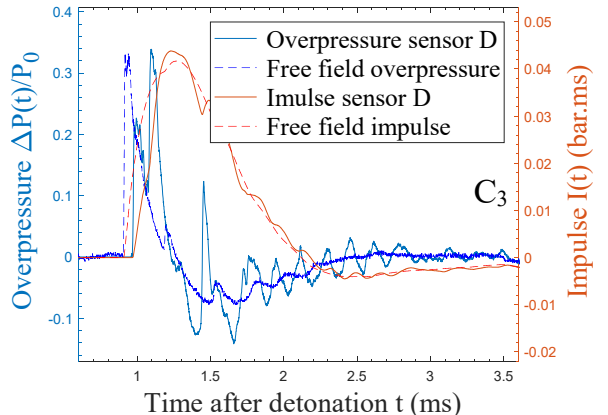

(b)

Figure 7: Pressure-time and impulse-time history of sensor D. Configurations: left: C2; right: $\mathrm{C} 3$.

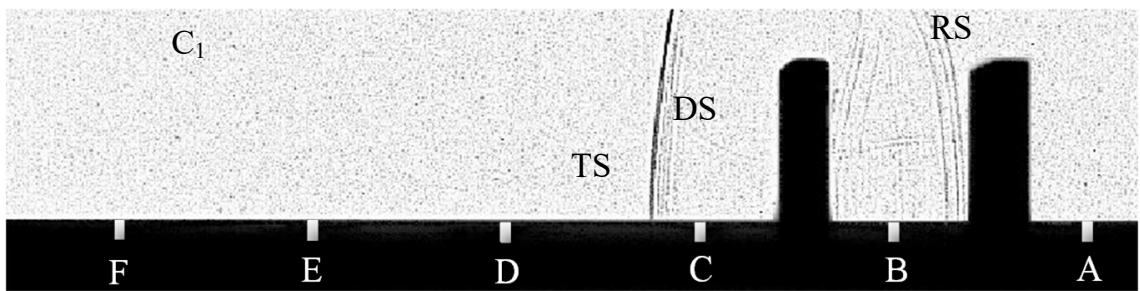

(a)

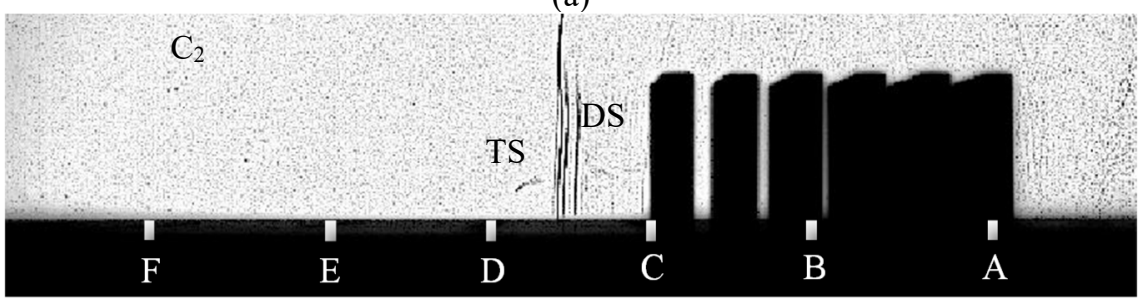

(b)

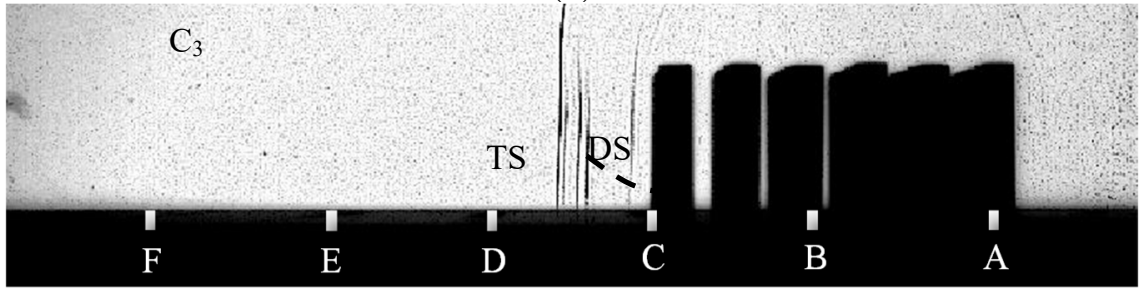

(c)

Figure 8: Experimental visualization after processing just downstream the obstructed area. (a) $\mathrm{t}=0.722 \mathrm{~ms}$; (b) $\mathrm{t}=0.852 \mathrm{~ms}$; and (c) $\mathrm{t}=0.851 \mathrm{~ms}$. RS: reflected shock; TS: transmitted shock; DS: diffracted shock. 


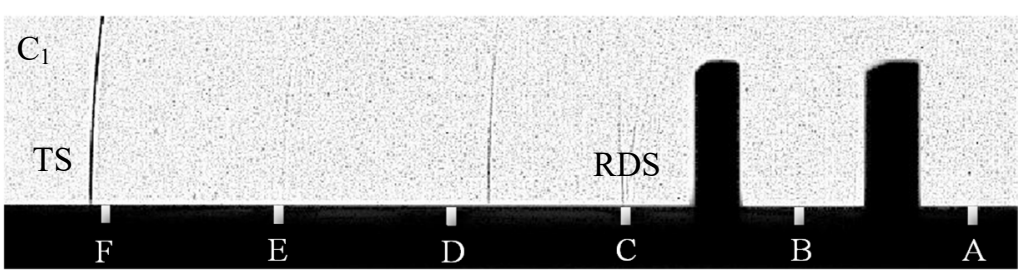

(a)

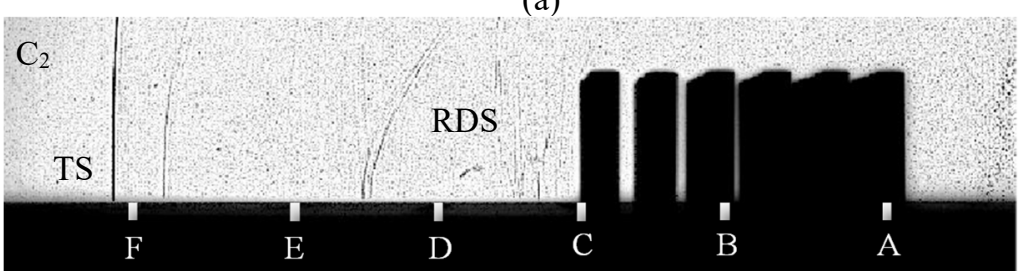

(b)

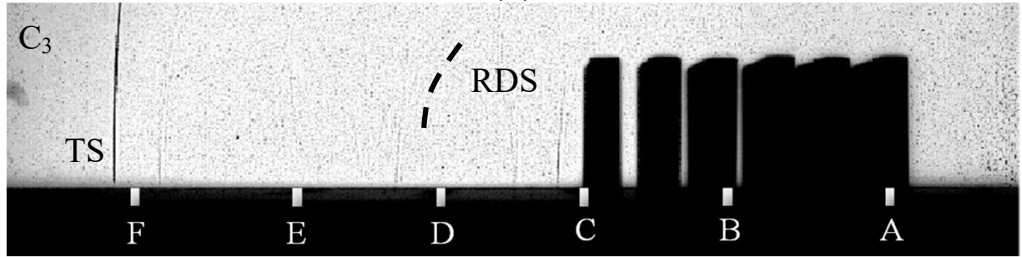

(c)

Figure 9: Experimental visualization after processing far downstream the obstructed area. (a) $\mathrm{t}=1.431 \mathrm{~ms}$; (b) $\mathrm{t}=1.502 \mathrm{~ms}$; and (c) $\mathrm{t}=1.501 \mathrm{~ms}$. TS: transmitted shock; RDS: reflection of diffracted shock.

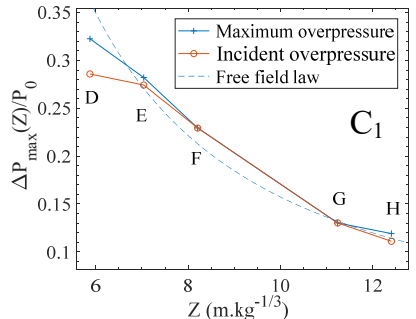

(a)

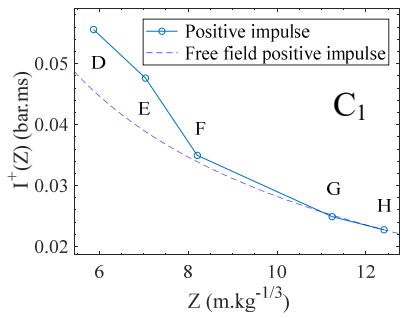

(d)

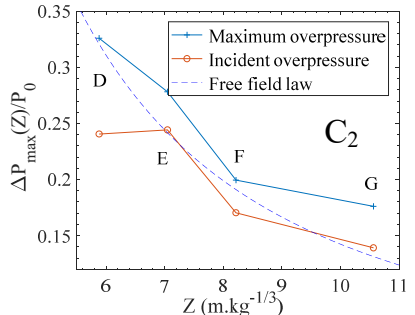

(b)

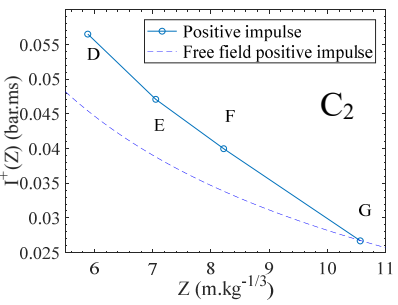

(e)

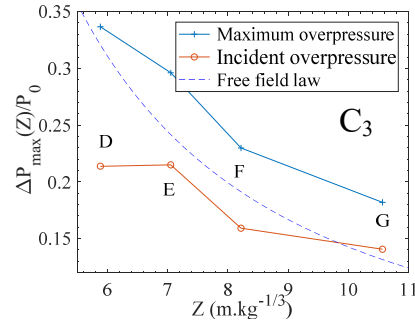

(c)

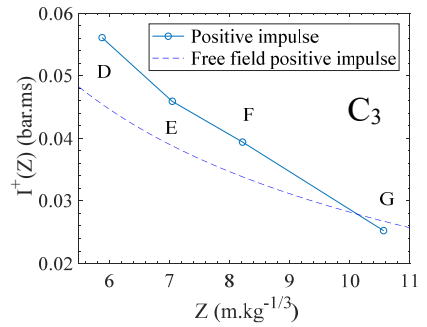

(f)

Figure 10: Overpressure and positive impulse against the reduced distance downstream the obstructed area. Configurations: left: $\mathrm{C} 1$; middle: $\mathrm{C} 2$; right: $\mathrm{C} 3$. 


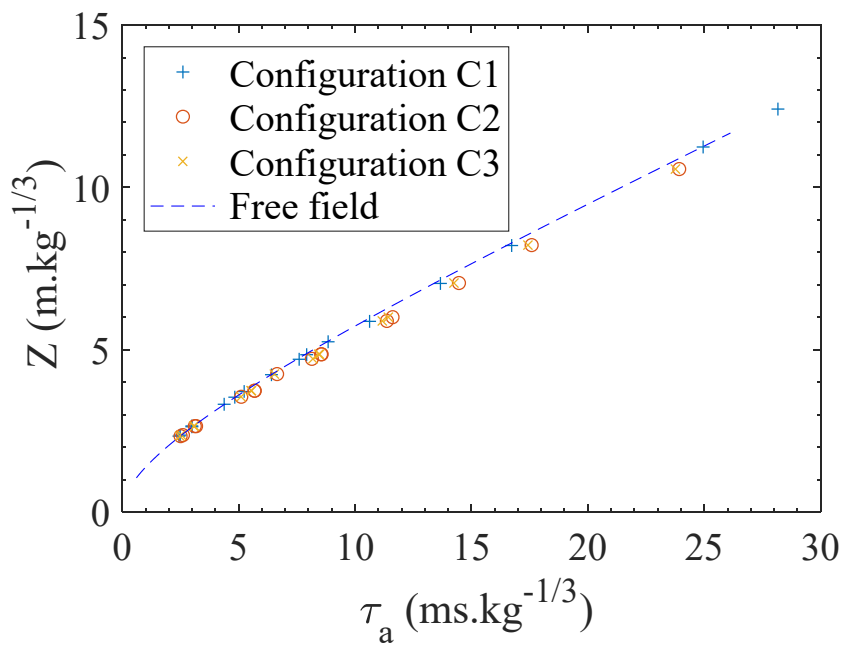

Figure 11: Reduced arrival time against reduced distance for the three configurations compared to free field.

The overpressure and impulse evolutions against the reduced distance are presented in Fig. 10. Configuration $\mathrm{C} 1$ does not really affect the downstream area far from the obstruction. In the two configurations $\mathrm{C} 2$ and $\mathrm{C} 3$, the maximum overpressure is reached by reflexions $\left(\Delta \mathrm{P}_{\text {inc }}<\Delta \mathrm{P}_{\max }\right)$. Moreover, the overpressure jump increases with the distance compared to the free field values. On the contrary, the positive impulse jump compared to the free field decreases with the distance increase.

As shown in Fig. 9(b) and 9(c), transmitted shock waves reach sensor F about $1.5 \mathrm{~ms}$ after detonation in $\mathrm{C} 2$ and $\mathrm{C} 3$, i.e. $0.07 \mathrm{~ms}$ later than in $\mathrm{C} 1$. This delay is illustrated in Fig. 11 with the evolution of the reduced arrival time against the reduced distance. The arrival time $\tau_{\mathrm{a}}$ is measured at the foot of the first peak overpressure, called "incident overpressure". The reduced time is defined by the time divided by the cubic root of the charge mass. As observed in visualization, the transmitted shock wave is slightly slowed down by the configurations $\mathrm{C} 2$ and $\mathrm{C} 3$ but not by the configuration $\mathrm{C} 1$.

\section{CONCLUSION}

In this study, the interaction of a spherical blast wave with three obstruction configurations is analysed. Experiments are performed at small scale using piezoelectric sensors to measure shock overpressure and an optical setup brings qualitative information to complete pressure profiles. The three configurations are matrices of finite circular cylinders. The obstruction degree and the kind of arrangement are the two main parameters.

Inside the obstacles area, the maximum overpressure is equivalent to the free field value but is reached due to reflections. At the entrance, the reflection on the first row of cylinders considerably increases the maximum overpressure. Just at the exit of the obstructed area, the overpressure is mitigated in the case of a regular arrangement and a great amount of cylinders. For all configurations, the positive impulse is increased inside the obstruction due to reflections. 
In the space downstream the obstruction, the first configuration does not affect the overpressure and the positive impulse domain. Concerning the configurations $\mathrm{C} 2$ and $\mathrm{C} 3$, the emergence of reflections from diffracted shock waves maintain the overpressure stronger than in free field and can increase far downstream. On the contrary, the positive impulse tends to decrease down to the free field value when the distance from the obstruction increases. It was observed that the regular arrangement and the staggered arrangement are quite similar as noted by Suzuki et al. [12] concerning effect on overpressure. As it was observed in previous works [5], the shock front speed is mitigated after crossing the two configurations $\mathrm{C} 2$ and $\mathrm{C} 3$.

\section{ACKNOWLEDGEMENT}

This study has been carried out in the laboratory Prisme within the framework of a contract with the CEA of Grammat.

\section{REFERENCES}

[1] Ben-Dor, G., Shock Wave Reflection Phenomena, 2nd ed., Springer-Verlag: Berlin, 2007.

[2] Wang, X. et al., High-fidelity simulations of blast loadings in urban environments using an overset meshing strategy. Shock Waves, 27(3), pp. 409-422, 2017.

DOI: 10.1007/s00193-016-0680-x.

[3] Fouchier, C., Laboureur, D., Youinou, L., Lapebie, E. \& Buchlin, J.M., Experimental investigation of blast wave propagation in an urban environment. Journal of Loss Prevention in the Process Industries, 49, pp. 248-265, 2017.

DOI: $10.1016 /$ j.jlp.2017.06.021.

[4] Rose, T.A. \& Smith, P.D., Influence of the principal geometrical parameters of straight city streets on positive and negative phase blast wave impulses. International Journal of Impact Engineering, 27(4), pp. 359-376, 2002.

DOI: $10.1016 / \mathrm{S} 0734-743 \mathrm{X}(01) 00060-4$.

[5] Chaudhuri, A., Hadjadj, A., Sadot, O. \& Ben-Dor, G., Numerical study of shock-wave mitigation through matrices of solid obstacles. Shock Waves, 23(1), pp. 91-101, 2013. DOI: 10.1007/s00193-012-0362-2.

[6] Berger, S., Sadot, O. \& Ben-Dor, G., Experimental investigation on the shock-wave load attenuation by geometrical means. Shock Waves, 20(1), pp. 29-40, 2010. DOI: $10.1007 / \mathrm{s} 00193-009-0237-3$.

[7] Skews, B.W., Draxl, M.A., Felthun, L. \& Seitz, M.W., Shock wave trapping. Shock Waves, 8(1), pp. 23-28, 1998. DOI: 10.1007/s001930050095.

[8] Wan, Q. \& Eliasson, V., Numerical study of shock wave attenuation in twodimensional ducts using solid obstacles: How to utilize shock focusing techniques to attenuate shock waves. Aerospace, 2(2), pp. 203-221, 2015.

DOI: 10.3390/aerospace2020203.

[9] Rogg, B., Hermann, D. \& Adomeit, G., Shock-induced flow in regular arrays of cylinders and packed beds. International Journal of Heat and Mass Transfer, 28(12), pp. 2285-2298, 1985. DOI: 10.1016/0017-9310(85)90047-X.

[10] Epstein, D.B. \& Kudryavtsev, A.N., Shock and blast wave propagation through a porous barrier. 28th International Symposium on Shock Waves, ed. K. Kontis, Springer: Berlin, pp. 537-542, 2012.

[11] Abe, A., Takayama, K. \& Itoh, K., Experimental and numerical study of shock wave propagation over cylinders and spheres. Transactions on Modelling and Simulation, 30, 2001. DOI: 10.2495/CMEM010201. 
[12] Suzuki, K. et al., Experimental studies on characteristics of shock wave propagation through cylinder array. The ISAS Report, 676, 2000.

[13] Rigby, S.E., Tyas, A., Fay, S., Clarke, S.D. \& Warren, J.A., Validation of semiempirical blast pressure predictions for far field explosions: Is there inherent variability in blast wave parameters? 6th International Conference on Protection of Structures against Hazards, Tianjin, China, 2014.

[14] Maillot, Y., Sochet, I., Vinçont, J.-Y. \& Grillon, Y., Experimental evaluation of a shock wave propagation impacting surface irregularity. MABS, 25, 2018.

[15] Langlet, A., Souli, M., Aquelet, N., Pennetier, O. \& Girault, G., Air blast reflecting on a rigid cylinder: simulation and reduced scale experiments. Shock Waves, 25(1), pp. 47-61, 2015. DOI: 10.1007/s00193-014-0531-6.

[16] Hargather, M.J. \& Settles, G.S., Retroreflective shadowgraph technique for large-scale flow visualization. Applied Optrics, 48(22), p. 4449, 2009.

DOI: 10.1364/AO.48.004449. 